\title{
Combined otoplasty technique utilizing posterior scoring of the auricular cartilage for correction of prominent ears
}

\author{
Mohamed A Al-Badawy, MD \\ Department of Plastic Surgery, Suez Canal University, Suez, Egypt.
}

\begin{abstract}
Prominent ears are a common congenital deformity of the external ear with an incidence of $5 \%$. Over 200 otoplasty techniques have been described in the current literature. The anterior scoring technique of the ear cartilage is the most commonly used method. However, this technique has many complications as hematoma, skin necrosis, chondritis and irreparable cartilage irregularities. The aim of this study is to evaluate a combined otoplasty technique depending on scoring of the ear cartilage on its posterior surface. Thirty six patients with prominent ears were managed with this technique with very good results in (83.35\%) and good results in $(16.65 \%)$, there were no major complications, but only few minor complications, and patients were very satisfied in (94.45\%) and satisfied in (5.55\%).
\end{abstract}

\section{Introduction:}

Prominent ears are the most common congenital deformity in the head and neck region, ${ }^{1}$ with an incidence of $5 \%$ in the white population. There is no apparent sex predilection for prominent ears. Since Luckett's original description in 1910, the anatomical features associated with prominent ears include absence of an adequate antihelical fold, presence of a large deep conchal bowl, inadequate definition of helical rim and abnormalities of the lobule.

Although prominent ears is a benign condition, it can cause considerable psychological trauma to children ${ }^{2-4}$ and to avoid this, the majority of patients are operated on around the age of 3-6 years before starting school. However, because of the importance of the cosmetic appearance and the patient cooperation during surgery, most surgeons prefer to operate at the age of 5 years. 5,6

The goals of surgical correction of prominent ears include natural antihelical and scaphal folding, conchal reduction, conchal setback and lobule setback.

Over 200 techniques have been described for the surgical correction of prominent ears. ${ }^{5}$ This means that there is no ideal technique exists and that new techniques and modifications will continue to evolve. Otoplasty techniques can be divided into two categoris: cartilage-cutting and cartilage-sparing. The cartilage-cutting techniques include cartilage incisions, wedge excision and abrasion or scoring of either the anterior or the posterior surface of the ear cartilage. The cartilagesparing techniques represent suturing of the cartilage only in an attempt to preserve the cartilage support and minimize its contour irregularities.

The anterior scoring technique of the ear cartilage is the most commonly used method. 7,8 However, there is an increasing criticism of this technique because of its high complication rate, that result from the anterior dissection causing anterior hematoma that may lead to anterior skin necrosis followed by chondritis and irreparable irregularities of the cartilage. ${ }^{9}$

The aim of this study is to evaluate a combined otoplasty technique for the correction of prominent ears utilizing scoring of the auricular cartilage on its posterior surface, followed by mattress suturing (Mustardé) of the cartilage to create the antihelical fold and then concha-mastoid suturing to reduce the angle between concha and mastoid. 


\section{Patients and methods:}

Between November 2006 and January 2010, thirty six patients with prominent ears were managed with combined otoplasty technique utilizing posterior scoring of the ear cartilage. 20 patients were males and 16 patients were females. The age of the patients ranged between (5-35) years. 26 patients had bilateral prominent ears, while in 10 patients the deformity was unilateral.

All of the patients had unfolding of the antihelix, either alone or with conchal hypertrophy. The follow-up of the patients ranged from 6-18 months.

Surgical technique: the helical rim is folded back against the head to visualize the area of the new antihelix followed by marking of the borders of the created antihelix by marker pen Figure(1).

The surgery is done under local anesthesia, often with sedation. In young children, general anesthesia may be required. The posterior surface of the auricle is infiltrated with xylocaine $2 \%$ and adrenaline 1:200000, then a linear surgical incision is done on the posterior surface of the ear $1-1.5 \mathrm{~cm}$ above the retroauricular fold, then undermining of the skin on the posterior surface of the auricle and

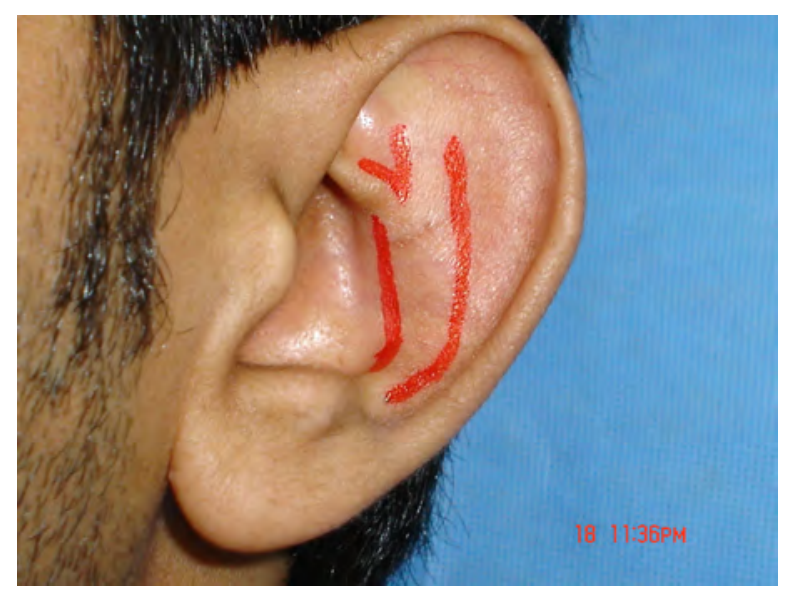

Figure(1): Marking of the site of the new antihelix. over the mastoid. Six 27 gauge needles dipped in methylene blue are passed across the marked lines anteriorly on the borders of the antihelix, passing to the posterior surface of the cartilage, then the cartilage area bordered by the needles posteriorly is scored by partial thickness excision of the cartilage using a scalpel. A three prolene $4 / 0$ horizontal mattress sutures are passed on the borders of the scored area Figure(2), then the mattress sutures are tied, determining the binding of the antihelix, usually these sutures are tied without tension. Sometimes, it is necessary to correct a very deep concha by excising a small part (fullthickness) of the conchal cartilage between 2$5 \mathrm{~mm}$ wide at the superolateral border of the concha. The concha is sutured to the periosteum over the mastoid with $4 / 0$ prolene. The redundant skin on the posterior surface of the auricle is excised. When necessary, the posterior surface of the helical tail was exposed for lobule replacement. The skin incision was closed using subcuticular prolene 5/0 suture. A dressing of petroleum jelly gauze was applied. An elastic bandage (not so tight) is worn for 7 days, followed by head band during the night for 3 months.

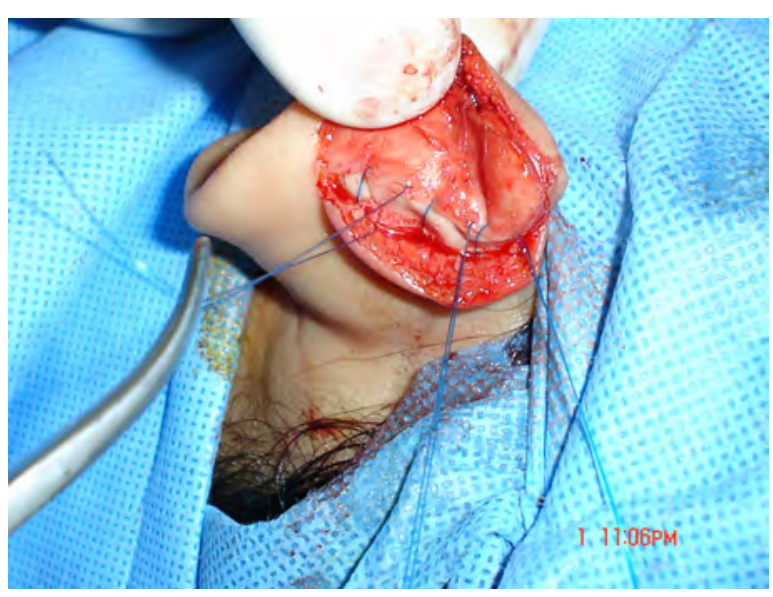

Figure (2): Scoring of the posterior surface of the ear cartilage opposite the antihelix, followed by Mustardé mattress suturing. 


\section{Results:}

The results of otoplasty were assessed using the guiding principles of McDowell, ${ }^{10}$ as follows:

(1) Any protrusion in the upper $1 / 3$ of the ear must be corrected.

(2) From front view, the helix of both ears should be seen beyond the antihelix.

(3) The antihelix should have a smooth and regular line throughout.

(4) The postauricular sulcus should not be markedly decreased.

(5) The ear should not be placed too close to the head. Posterior measurement from the outer edge of the helix to the mastoid should be $10-12 \mathrm{~mm}$ at the top, $16-18 \mathrm{~mm}$ in the middle $1 / 3$, and $20-22 \mathrm{~mm}$ in the lower $1 / 3$.

(6) The position of the two ears should match fairly closely.

Also, patient questionnaire about the result of otoplasty was done as follows:
1. Pain when the ear is touched.

2. Hypersensitivity to cold.

3. Loss of sensation on the ear.

4. Normal or abnormal shape of the ear.

5. Symmetry of both ears.

There were no major complications as bleeding, hematoma, cartilage infection, skin necrosis or wound dehiscence. There were no keloidal scarring, asymmetry or unsatisfactory aesthetic results. However, there were 2 cases $(5.55 \%)$ of mild hypersensitivity to touch and cold, 2 cases $(5.55 \%)$ of mild skin infection (erythema) which resolved by antibiotic treatment and 2 cases $(5.55 \%)$ of extrusion of the concha-mastoid sutures which occurred late after 3 months of the operation and doesn't result in recurrence of the deformity Table(1).

The results were very good in 30 pateints $(83.35 \%)$ and good in 6 patients $(16.65 \%)$.

Thirty four patients $(94.45 \%)$ were very satisfied with the results and 2 patients $(5.55 \%)$ were satisfied Table(2).

Table (1): Complications after combined otoplasty technique.

\begin{tabular}{|l|c|c|}
\hline \multicolumn{1}{|c|}{ Complication } & Number & $\%$ \\
\hline Bleeding & 0 & 0 \\
\hline Hematoma & 0 & 0 \\
\hline Cartilage infection & 0 & 0 \\
\hline Skin necrosis & 0 & 0 \\
\hline Wound dehiscence & 0 & 0 \\
\hline Keloidal scar & 0 & 0 \\
\hline Asymmetry & 0 & 0 \\
\hline Unsatisfactory aesthetic results & 0 & 5.55 \\
\hline Hypersensitivity to touch and cold & 2 & 5.55 \\
\hline Skin infection & 2 & 5.55 \\
\hline Suture extrusion & 2 & 16.65 \\
\hline Total & 6 & \\
\hline
\end{tabular}

Table (2): Patient satisfaction after otoplasty technique.

\begin{tabular}{|l|c|c|}
\hline Satisfaction & Number & $\%$ \\
\hline Very satisfied & 34 & 94.45 \\
\hline Satisfied & 2 & 5.55 \\
\hline Not satisfied & 0 & 0 \\
\hline
\end{tabular}


Table (3): Complication rates for published series and for this study.

\begin{tabular}{|c|c|c|c|c|c|c|c|}
\hline Study & $\begin{array}{l}\text { No. of } \\
\text { patients }\end{array}$ & Method & $\underset{(\%)}{\operatorname{Hematoma}}$ & $\begin{array}{c}\text { Bleeding } \\
(\%)\end{array}$ & \begin{tabular}{|c|} 
Skin \\
necrosis \\
$(\%)$
\end{tabular} & $\begin{array}{c}\text { Suture } \\
\text { extrusion } \\
(\%)\end{array}$ & \begin{tabular}{|c|} 
Recurrence \\
or residual \\
deformity (\%)
\end{tabular} \\
\hline $\begin{array}{l}\text { Calder and } \\
\text { Naasan }^{7}(1994)\end{array}$ & 562 & Anterior scoring & & 2 & 1.4 & 0 & 8 \\
\hline Jeffery $^{9}$ (1999) & 118 & Anterior scoring & 3.4 & & 1.7 & 0 & 12.7 \\
\hline $\begin{array}{l}\text { Caouette-Laberge } \\
\text { et } \mathrm{al}^{8}(2000)\end{array}$ & 500 & $\begin{array}{l}\text { Anterior scoring } \\
\text { and sutures }\end{array}$ & 0.4 & 2.6 & 0 & & 5.7 \\
\hline $\operatorname{Erol}^{25}(2001)$ & 55 & $\begin{array}{c}\text { Anterior sculpting } \\
\text { and sutures }\end{array}$ & 0 & & & 1.8 & 7.2 \\
\hline $\begin{array}{l}\text { Robiony } \\
\text { et } \mathrm{al}^{26}(2001)\end{array}$ & 29 & $\begin{array}{c}\text { Anterior sculpting } \\
\text { and sutures }\end{array}$ & & & 17.2 & & 0 \\
\hline $\begin{array}{l}\text { Bulstrode } \\
\text { et } \mathrm{al}^{27} \text { (2003) }\end{array}$ & 114 & $\begin{array}{c}\text { Anterior sculpting } \\
\text { and sutures }\end{array}$ & 0 & 0.9 & 0 & 0 & 6.2 \\
\hline $\begin{array}{l}\text { Salgarello } \\
\text { et al }{ }^{19}(2007)\end{array}$ & 135 & $\begin{array}{l}\text { Anterior scoring } \\
\text { and sutures }\end{array}$ & 0 & 3 & & & 2 \\
\hline * This study & 36 & $\begin{array}{l}\text { Posterior scoring } \\
\text { and sutures }\end{array}$ & 0 & 0 & 0 & 5.55 & 0 \\
\hline
\end{tabular}

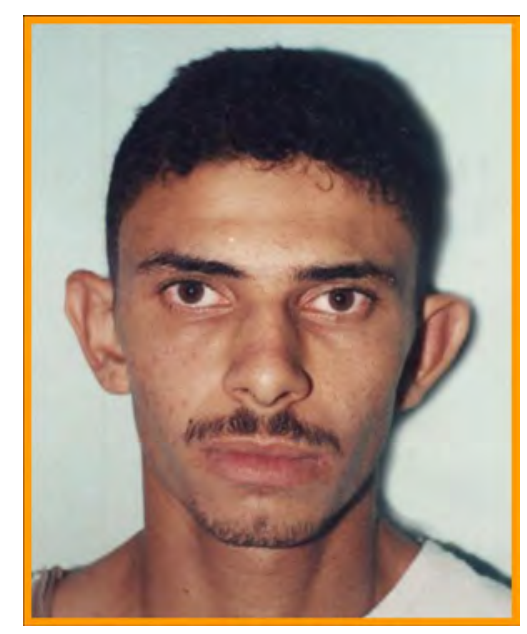

(A)

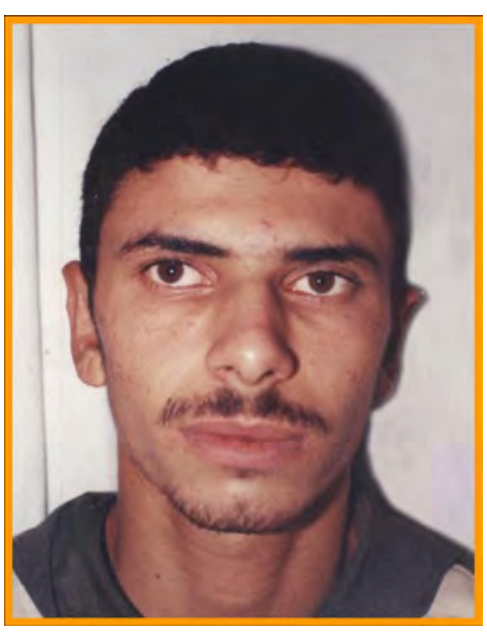

(B)

Figure (3): Male patient, 23 years old with bilateral prominent ears. (A) Preoperative AP view, (B) Postoperative AP view. 


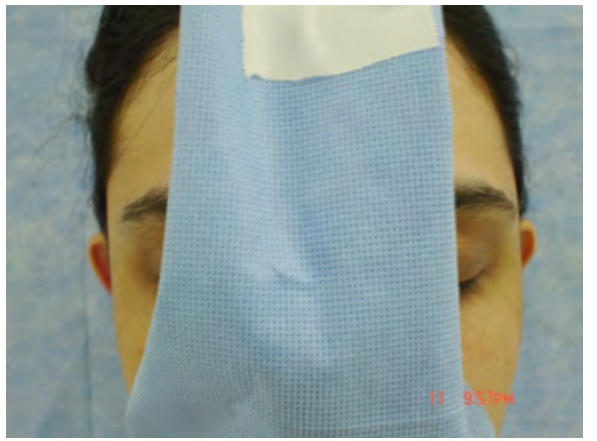

(A)

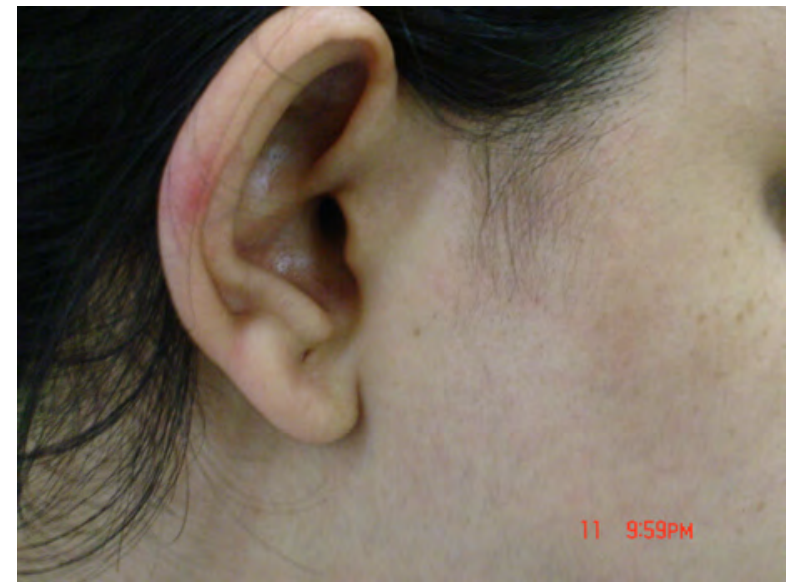

(B)

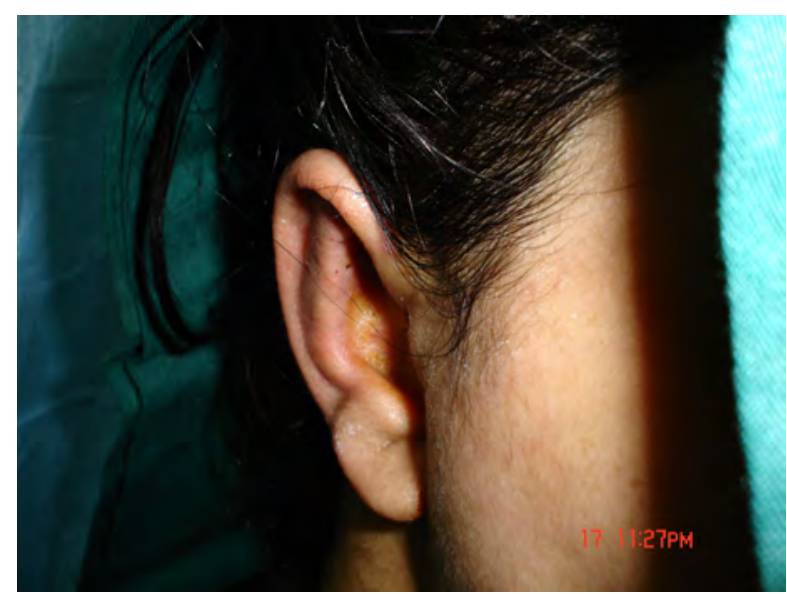

(D)

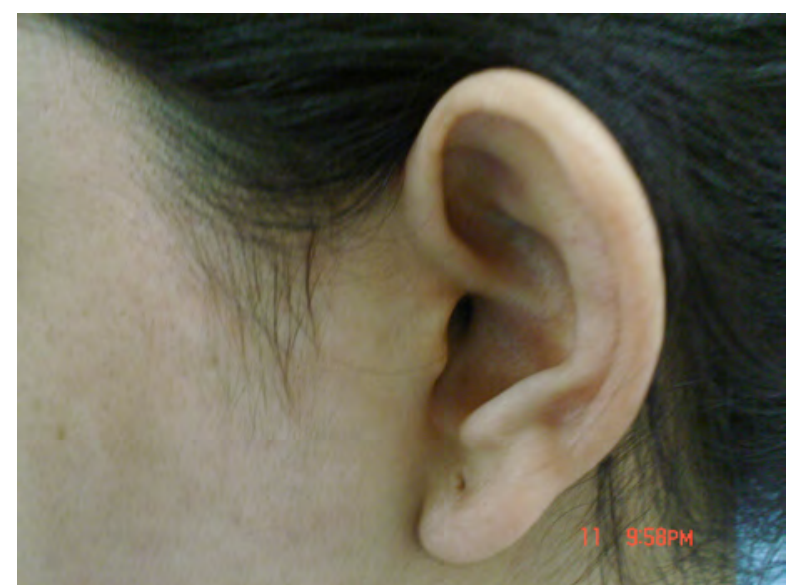

(C)

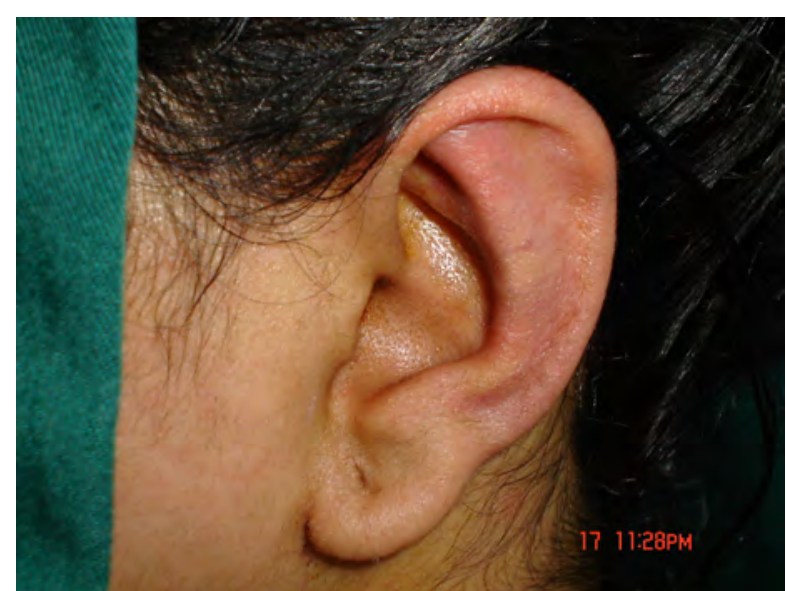

(E)

Figure (4): Female patient, 23 years old, with bilateral prominent ears, $(A, B, C)$ preoperative $A P, R t$ and Lt lateral views. (D, E) Postoperative Rt oblique and Lt lateral views. 


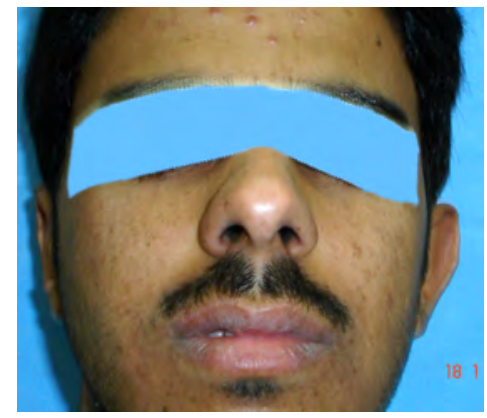

(A)

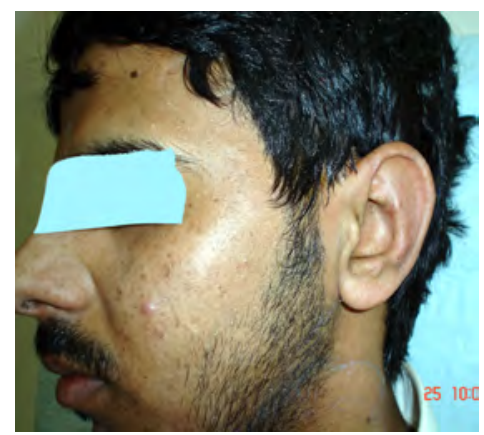

(D)

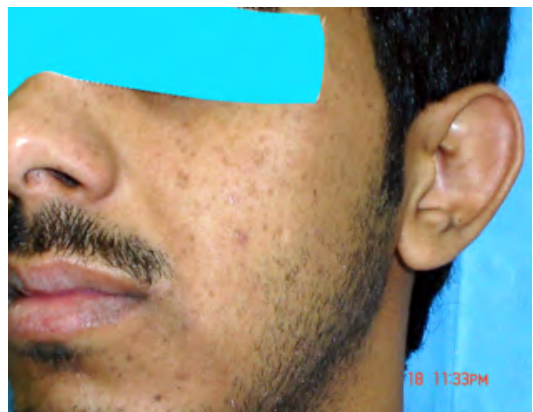

(B)

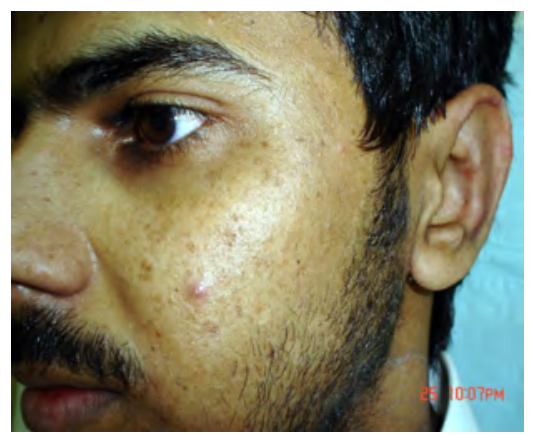

(E)

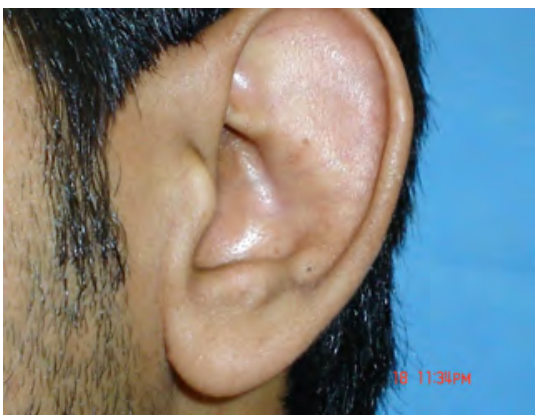

(C)

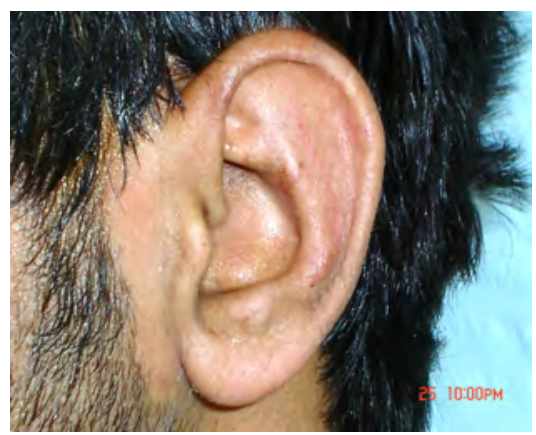

(F)

Figure (5): Male patient, 25 years old, with unilateral (Lt) prominent ear $(A, B, C)$ preoperative $A P, L t$ oblique and Lt (close) views. (D, E, F) Lt lateral, Lt oblique and Lt (close) views.

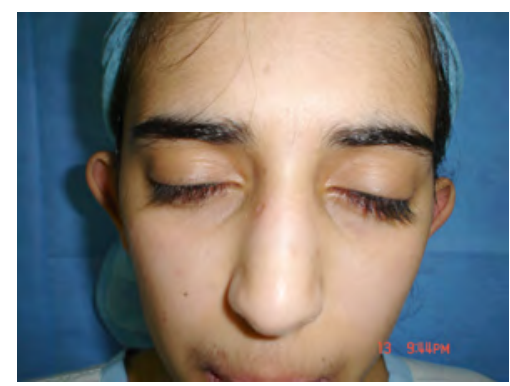

(A)

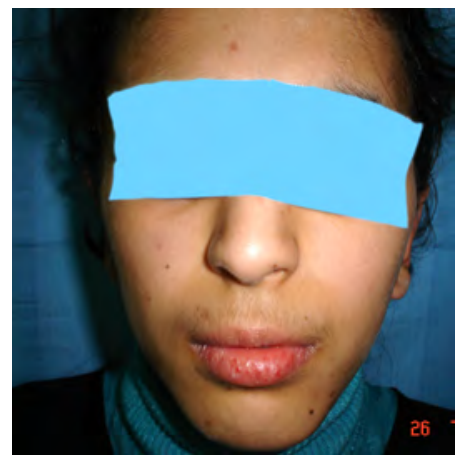

(D)

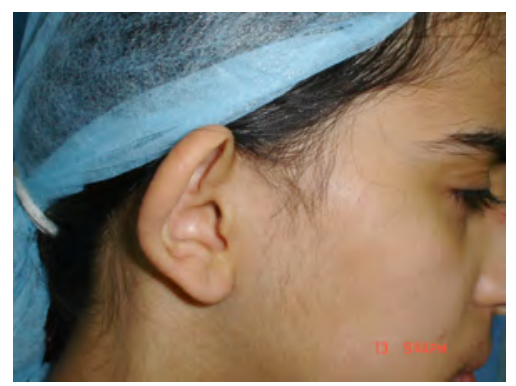

(B)

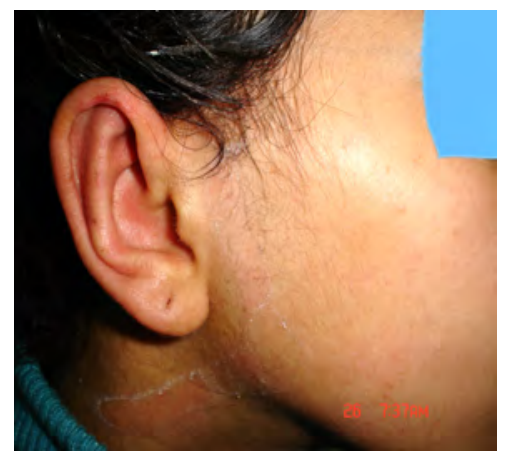

(E)

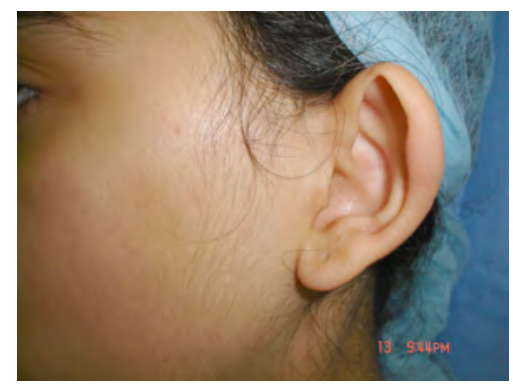

(C)

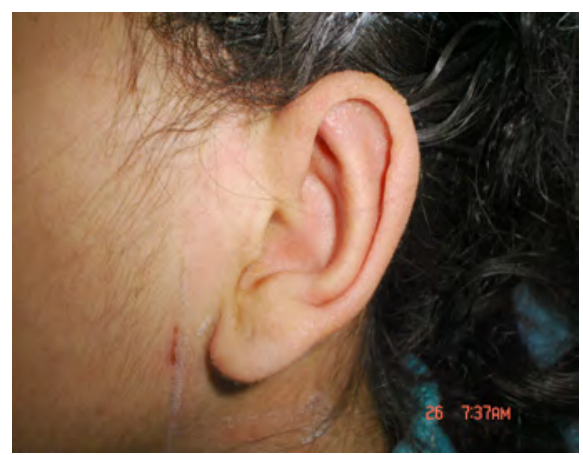

(F)

Figure (6): Female patient, 11 years old, with bilateral prominent ears. $(A, B, C)$ preoperative $A P$, Rt and Lt lateral views. (D, E, F) postoperative AP, Rt oblique and Lt lateral views. 


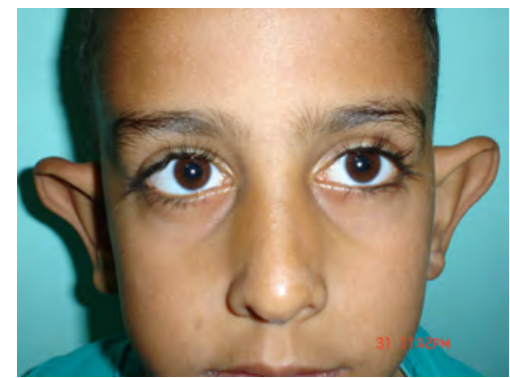

(A)

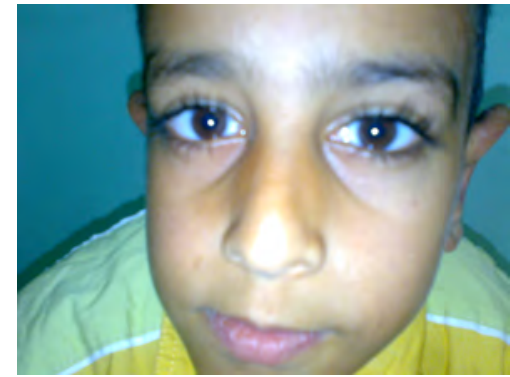

(D)

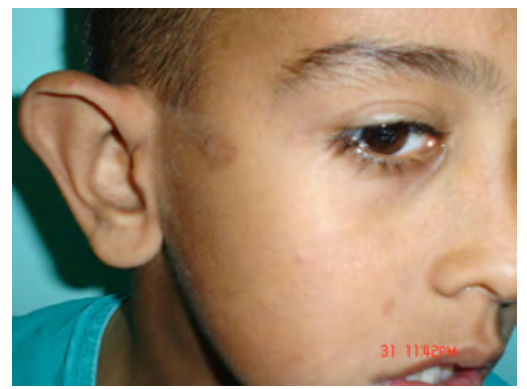

(B)

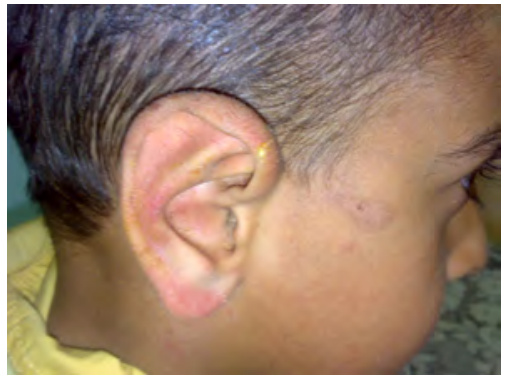

(E)

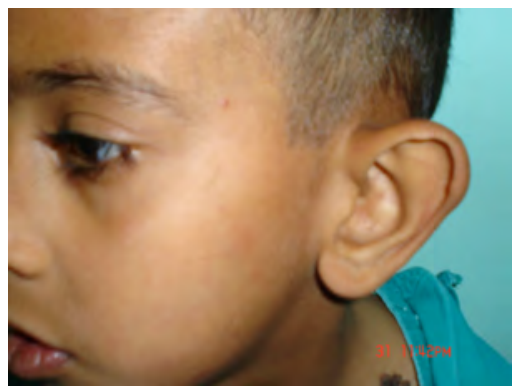

(C)

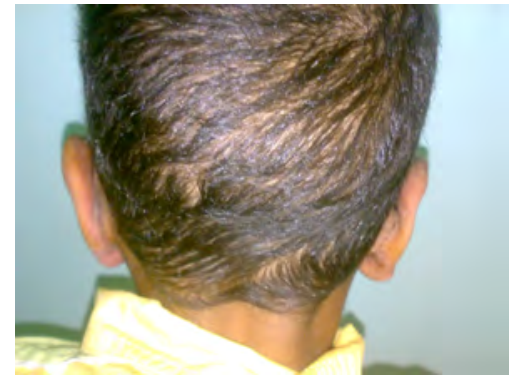

(F)

Figure (7): Male patient, 5 years old, with bilateral prominent ears. $(A, B, C)$ Preoperative AP, Rt and Lt oblique views. (D, E, F) Postoperative AP, Rt lateral and back views.

\section{Discussion:}

The goal of surgery for prominent ears is to produce symmetrical, natural-looking ears, with no obvious signs of surgery having been performed.

The first described aesthetic otoplasties were by Ely ${ }^{11}$ in 1881 and Luckett ${ }^{12}$ in 1910 and were examples of cartilage-cutting techniques. In 1963, Stenström ${ }^{13}$ described scoring of the anterior surface of the auricular cartilage to create an antihelical fold. Many different instruments have been used later for scoring of the cartilage including scalpels, rasps, abraders, diamond burr drills, AdsonBrown forceps, hypodermic needles and even bipolar cautery. In 1963, Mustardé14 described the use of multiple horizontal mattress sutures to recreate the antihelical fold. In 1968, Furnas ${ }^{15}$ described the use of concha-mastoid mattress sutures to decrease the projection of the concha. Tan, 16 in a retrospective study comparing the sculpting-only technique (Stenström) to the sutures-only technique (Mustardé), found a higher revision rate when using Mustardé sutures. The loss of correction of the cartilage may be due to the cutting of the suture material through the cartilage, and also in thick strong cartilage the use of sutures alone is often insufficient to control its intrinsic cartilage memory. Sculpting techniques involving cutting of the cartilage can irreversibly deform the shape of the ear due to unpredictable wound contraction forces and cartilage remodeling. In addition, sculpting techniques come with the risk of cartilage irregularities or sharp edges. 5,17 Subsequently different combinations of the previous two techniques have been developed to combine the best of both techniques with the aim of reducing suture complications and recurrences.

Caouette-Laberge et al, ${ }^{8}$ studied 500 cases of prominent ears which were managed by a cartilage incision and anterior scoring technique. Early complications were bleeding in 13 cases $(2.6 \%)$ and hematoma in 2 cases $(0.4 \%)$ and one wound dehiscence $(0.2 \%)$ and late complications as keloidal scar in 2 cases, residual deformity in 22 cases and asymmetry in 28 cases. Patients were very satisfied with the results in $(74 \%)$ of cases, satisfied in $(20.8 \%)$ dissatisfied in $(4.2 \%)$ and very dissatisfied in $(1 \%)$.

Yugueros and Friedland, ${ }^{18}$ studied 100 patients with prominent ears who were managed with combined otoplasty technique using anterior scoring of the cartilage, Mustardè mattress sutures and concha-mastoid suturing. Undercorrection was noted in 7 ears $(5 \%)$, secondary correction in 6 ears, suture extrusion in 19 ears (10\%) and no patients were dissatisfied with the final results. 
Salgarello et a ${ }^{19}$ performed a retrospective review of 135 patients with prominent ears who were managed with a combined technique using anterior scoring of the ear cartilage with Stenström otoabrader, Mustardè mattress sutures and conchal rim cartilage excision if a deep conchal bowel is present. Bleeding occurred in 9 cases (3\%), keloidal scar in 3 cases $(1 \%)$ and recurrence of the deformity in 6 cases $(2 \%)$.

Fritsch ${ }^{20}$ described the technique of "incisionless otoplasty" in which the anterior surface of the planned antihelical fold is scored percutaneously using 21-gauge hypodermic needle, Mustardè mattress sutures are placed percutaneously and the deep conchal bowel is addressed by endoscopically removing the soft tissue between the conchal bowel and mastoid and then placing the concha-mastoid sutures. However, this technique is not suitable for young children because their auricular cartilage is too soft, and the sutures cause accordionlike folding rather than smooth curving.

Bhatti and Donovan ${ }^{21}$ described sutureless otoplasty technique. Scoring of the anterior surface of the cartilage was done and no sutures are used except if only concha-mastoid suturing is indicated. Thirty four patients were managed with this technique. Bleeding occurred in 2 cases $(2.9 \%)$, infection in 1 case $(1.45 \%)$ and skin problems in 1 case $(1.45 \%)$. Twenty five patients were extremely satisfied, 8 patients were satisfied, and 1 patient not satisfied. However, six patients still felt that their ears were prominent.

Horlock et al 22 described the use of postauricular fascial flap as an adjunct to Mustardè and Furnas type otoplasty to avoid suture extrusion. Fifty-one patients were managed with this technique, and there were no hematomas but recurrence occurred in 8 ears $(8 \%)$, two patients requested further surgery and no patients developed suture extrusion.

Scuderi et $a^{23}$ described a technique of repositioning the posterior auricular muscle to address an increased cephaloauricular angle. The antihelix was managed with cartilage scoring and suturing for mild to moderate antihelical hypoplasia. The technique was used in 103 ears in 55 patients with no skin necrosis or suture extrusion but with asymmetry in 2 patients.

Hassanpour and Moosavizadeh ${ }^{24}$ used a technique utilizing cartilage incision at the border between the antihelix and scapha with posterior scoring of the scapha and anterior scoring of the antihelix region for management of 45 cases of prominent ears. There was mild asymmetry in one patient and the results were very good in 36 ears $(80 \%)$ and good in 7 ears $(15 \%)$.

The previous studies using anterior scoring of the auricular cartilage had a high complication rate that may result from the anterior dissection of the cartilage causing anterior hematoma that may lead to anterior skin necrosis followed by chondritis and this may result in irreparable cartilage irregularities. Eight percent of ears treated with anterior scoring retain some residual deformity due to an increased number of undercorrected ears after a longer period of follow-up. ${ }^{7}$

In this study, thirty six patients with prominent ears (62 ears), were managed with combined otoplasty technique utilizing posterior scoring of auricular cartilage and avoiding any full thickness incision or anterior scoring of the ear cartilage to avoid their complications. There were no major complications as bleeding, hematoma, cartilage infection, skin necrosis, wound dehiscence, asymmetry or unsatisfactory aesthetic results. However, some minor complications occurred as hypersensitivity to cold and touch in 2 cases $(5.55 \%)$, skin infection which resolved with antibiotic treatment in 2 cases $(5.55 \%)$ and suture extrusion in 2 cases $(5.55 \%)$ which occurred in the late postoperative follow-up and doesn't affect the final results after their removal. The results were very good in 30 patients $(83.35 \%)$ and good in 6 patients $(16.65 \%)$. Thirty four patients $(94.45 \%)$ were very satisfied with the results and 2 patients $(5.55 \%)$ were satisfied. Table(3), shows a comparison between the complication rates of this study and that of some other published studies. 


\section{Conclusion:}

The combined otoplasty technique utilizing posterior scoring of the ear cartilage is a good technique for correction of prominent ears with low complication rate and high patient satisfaction with the results.

\section{References:}

1- Bardach J: Surgery for congenital and acquired malformation of the auricle. In: Otolayngology: Head and Neck Surgery. C.W. Cummings, J.M. Fredrickson, L.A. Harker, C.J. Krause, and D.E. Schuller (Editors); St. Louis: Mosby (Publisher); 1986; p. 2861.

2- Bogetti P, Boltri M, Spagnoli G, et al: Otoplasty for prominent ears with combined techniques. Eur J Plast Surg 2003; 26: 144148.

3- Adamson PA, Strecker HD: Otoplasty techniques. Facial Plast Surg 1995; 11 : 284-299.

4- Macgregor FC: Ear deformities: Social and psychological implications. Clin Plast Surg 1978; 5: 347-350.

5- Kelley P, Hollier L, Stal S: Otoplasty: Evaluation, technique, and review. $J$ Craniofac Surg 2003; 14: 643-653.

6- Ohlsén L, Vedung S: Reconstructing the antihelix of protruding ears by perichondrioplasty: A modified technique. Plast Reconstr Surg 1980; 65: 753-762.

7- Calder JC, Naasan A: Morbidity of otoplasty: A review of 562 consecutive cases. $\mathrm{Br} \mathrm{J}$ Plast Surg 1994; 47: 170.

8- Caouette Laberge L, Guay N, Bortoluzzi P, et al: Otoplasty: Anterior scoring technique and results in 500 cases. Plast Reconstr Surg 2000; 105 (2): 504-515.

9- Jeffery SL: Complications following correction of prominent ears: An audit review of 122 cases. Br J Plast Surg 1999; 52: 588 .

10-McDowell AJ: Goals in otoplasty for protruding ears. Plast Reconstr Surg 1968; 41: 17-27.

11-Ely ET: An operation for prominence of the auricles. Arch Otology 1881; 10: 97.

12-Luckett WH: A new operation for prominent ears based on the anatomy of the derfomity. Surg Gynec Obst 1910; 10: 635-637.

13-Stenström SJ: A "natural" technique for correction of congenitally prominent ears.
Plast Reconstr Surg 1963; 32: 509-518.

14-Mustardé JC: The correction of prominent ears using simple mattress sutures. $\mathrm{Br} \mathrm{J}$ Plast Surg 1963; 16: 170-176.

15-Furnas DW: Correction of prominent ears by concha mastoid sutures. Plast Reconstr Surg 1968; 42: 189-193.

16-Tan KH: Long-term survey of prominent ear surgery: A comparison of two methods. Br J Plast Surg 1986; 39: 270-273.

17-Vuyk HD: Cartilage-sparing otoplasty: A review with long-term results. $J$ Laryngol Otol 1997; 111: 424-430.

18-Yugueros P, Friedland JA: Otoplasty: The experience of 100 consecutive patients. Plast Reconstr Surg 2001; 108 (4): 10451051.

19-Salgarello M, Gasperoni C, Montagnese A, et al: Otoplasty for prominent ears: A versatile combined technique to master the shape of the ear. Otolaryngol Head Neck Surg 2007; 137: 224-227.

20-Fritsch MH: Incisionless otoplasty. Facial Plast Surg 2004; 20: 267-270.

21-Bhatti AZ, Donovan DO: Sutureless otoplasty by scoring of the cartilage: A study in 34 patients. Br J Oral Maxillofac Surg 2007; 45: 217-220.

22-Horlock N; Misra A; Gault DT: The postauricular facial flap as an adjunct to Mustardè and Furnas type otoplasty. Plast Reconstr Surg 2001; 108 (6): 1487-1490.

23-Scuderi N, Tenna S, Biotonti A, et al: Repositioning of posterior auricular muscle combined with conventional otoplasty: A personal technique. J Plast Reconstr Aesthet Surg 2007; 60: 201-204.

24-Hassanpour SE, Moosavizadeh: Posterior scoring of the scapha as a refinement in aesthetic otoplasty. $J$ Plast Reconstr and Aesthet Surg 2001; 63: 78-86.

25-Erol OO: New modification in otoplasty: Anterior approach. Plast Reconstr Surg 2001; 107: 193-202.

26-Robiony M, Costa F, Politi M: A technique for remodeling the antihelix to correct the prominent ear. J Oral Maxillofac Surg 2001; 59: 9-13.

27-Bulstrode NW; Huang S; Martin DL: Otoplasty by percutaneous anterior scoring. Another twist to the story: A long-term study of 114 patients. Br J Plast Surg 2003; 56: 145-149. 